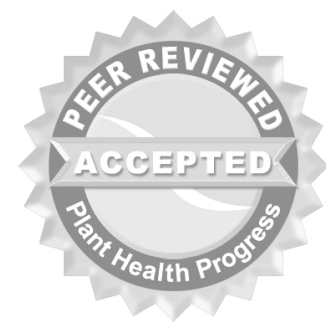

(C) 2013 Plant Management Network.

Accepted for publication 11 January 2012. Published 1 March 2013.

\title{
First Report of Tobacco ringspot virus Infecting Ajuga reptans in Ohio
}

\author{
John R. Fisher, Ohio Department of Agriculture, Plant Health \\ Diagnostic Laboratory, Plant Health Division, Reynoldsburg, $\mathrm{OH}$ \\ 43068
}

Corresponding author: John R. Fisher. jfisher@agri.ohio.gov

Fisher, J. R. 2013. First report of Tobacco ringspot virus infecting Ajuga reptans in Ohio. Online. Plant Health Progress doi:10.1094/PHP-2013-0301-01-BR.

Tobacco ringspot virus (TRSV) is the type species of the Nepovirus genus of the Family Secoviridae. The virus has a bipartite, single-stranded positive sense RNA genome that is translated into two polyproteins. The RNA 1 polyprotein has six domains and includes the RNA dependent RNA polymerase at its 3' terminal. The RNA 2 polyprotein has three domains and includes the coat protein at its 3 ' terminal. TRSV has a broad host range and is transmitted by longidorid nematodes (3).

In the fall of 2011, a bugleweed (Ajuga reptans 'Bronze Beauty') sample exhibiting a very subtle virus-like mottle symptom on new growth (Fig. 1) was submitted to the Ohio Plant Diagnostic Network as part of a Farm Bill funded survey of perennial viruses. The sample tested positive for TRSV and negative for the Potyvirus group, Alfalfa mosaic virus (AMV), Arabis mosaic virus, Cucumber mosaic virus (CMV), Impatiens necrotic spot virus, Tobacco mosaic virus, Tobacco streak virus (TSV), Tomato mosaic virus, Tomato ring spot virus, and Tomato spotted wilt virus by ELISA using commercially produced antibodies (Agdia Inc., Elkhart, IN). The sample also tested negative for Tobacco rattle virus by RT-PCR. Previously AMV, CMV, and TSV have been reported in bugleweed in Ohio (1) but this is the first confirmed report of TRSV infecting $A$. reptans in the state.

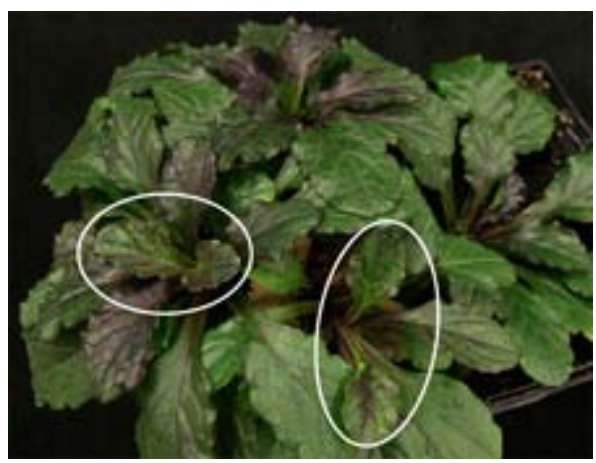

Fig. 1. Subtle virus-like mottle symptom observed on new growth of $A$. reptans 'Bronze Beauty' plant infected with TRSV.

For immunocapture reverse transcription (IC-RT), magnetic beads conjugated with sheep anti-rabbit IgG were incubated with polyclonal rabbit anti-TRSV IgG (Agdia Inc., Elkhart, IN) as previously described (2). Leaf tissue samples were extracted, incubated with TRSV-IgG conjugated beads, washed, and cDNAs synthesized from bound virions (2). Two full length and two partial TRSV RNA 1 sequences (accession \#: U50869.1, NCo05097.1, AJ698718.1, EF528581.1), and two full length and three partial TRSV RNA 2 sequences (accession \#: AY363727.1, NCo05096.1, HQ446459.1, HQ446463.1, HQ446464.1) were used to design two sets of primers to amplify the RNA 
dependent RNA polymerase (RdRp) region of RNA 1 (TRSVRdRpfwd6oo5: 5'GCTGATTGCGACCCAATACCTC-3'; TRSVRdRprev7067: 5'-

GCTACCAATCCTGGTTAGAAG-3') and the coat protein (CP) region of RNA 2 (TRSVCPfwd2442: 5'-GGTGACACTTTCGCCATTG-3'; TRSVCPrev3452: 5'GGACAAAACACCTAACTAAAG-3'; Integrated DNA Technologies Inc., Coralville, IA). Five $\mu \mathrm{l}$ of cDNA or sterile water was used as template for individual PCR reactions. Amplification was done in $25 \mu$ reactions $(1.5 \mathrm{mM}$ $\mathrm{MgCl}_{2}, 0.2 \mathrm{mM}$ dNTP mix, $0.2 \mu \mathrm{M}$ primer pair, 0.625 units GoTaq Flexi polymerase (Promega Inc., Madison, WI) using the cycling parameters: $94^{\circ} \mathrm{C}(2$ min), 30 cycles of $94^{\circ} \mathrm{C}(45 \mathrm{sec}), 51^{\circ} \mathrm{C}(30 \mathrm{sec}), 47^{\circ} \mathrm{C}(30 \mathrm{sec}), 72^{\circ} \mathrm{C}(6 \mathrm{osec})$, and a final extension of $72^{\circ} \mathrm{C}(10 \mathrm{~min})$.

cDNAs synthesized from immunocaptured virions amplified strong, distinct products of expected size with the RdRp and CP primers (Fig. 2). The amplicons were excised, purified from the agarose, and cloned into pGEM-T vector as previously described (2). Colonies were screened for inserts which were subsequently sequenced. Sequences were assembled and subjected to pairwise and multiple sequence alignments (2). Eight RdRp and six CP amplicon clones were sequenced and the processed sequences deposited in GenBank (accession numbers: JX848602-JX848615). All of the RdRp clones were 1055 nucleotides (nt) and all of the CP clones were $1013 \mathrm{nt}$. RdRp clones shared 99.4-100\% nt identity with a mean identity of $99.7 \%$, with CP clones sharing $99.7-99.9 \% \mathrm{nt}$ identity with a mean of $99.8 \%$. A BLASTn search of the NCBI database using default algorithm settings identified a single sequence (accession \# U50869.1) with $89 \%$ nt identity (100\% query coverage) to the RdRp clones, and a single sequence (accession \# AY363727.1) with 97\% nt identity (100\% query coverage) to the $\mathrm{CP}$ clones. When translated, the RdRp clones corresponded to amino acids (aa) 1969-2301 of the RNA polymerase region of the RNA 1 polyprotein and shared $96.1 \%$ predicted aa identity with accession \# U50869.1. The CP clones corresponded to aa 774-1101 of the coat protein region of the RNA 2 polyprotein and shared $\mathbf{9 9 . 1 \%}$ predicted aa identity with accession \# AY363727.1. These results represent the first confirmed report of TRSV infecting bugleweed in Ohio and expand the known host range of the virus for the state. Growers should also benefit from these results by gaining awareness of TRSV as a potential threat to their operations, and of bugleweed as a perennial reservoir for the virus.

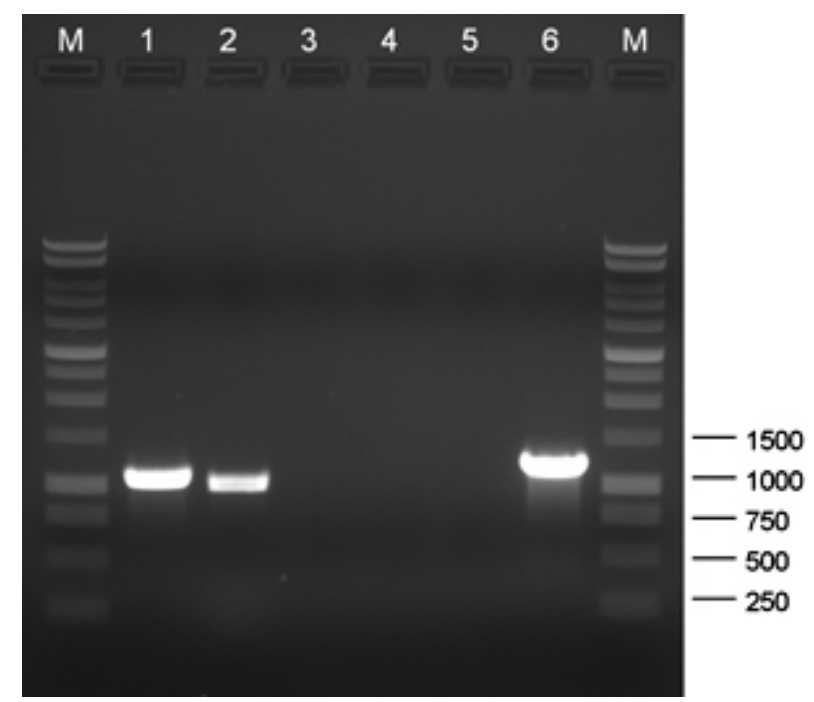

Fig. 2. PCR detection of TRSV from cDNAs synthesized from

immunocaptured virions with RdRp-specific primers (Lane 1) and CPspecific primers (Lane 2). Water controls with RdRp primers (Lane 3), CP primers (Lane 4), and M13 plasmid primers (Lane 5). TSV CP clone used as a positive PCR control with $\mathrm{M} 13$ primers (Lane 6 ). $\mathrm{M}=1 \mathrm{~Kb}$ DNA ladder (250, 500, 750, 1000, and 1500 bp markers indicated). Electrophoresis was done in $0.8 \%$ agarose at 100 volts for 60 minutes in 1 X TAE buffer. Gel was stained with ethidium bromide. 


\section{Literature Cited}

1. Fisher, J. R., and Nameth, S. T. 2000. Virus assessment of Ajuga reptans cultivars reveals Alfalfa mosaic, Tobacco streak, and Cucumber mosaic (CMV) viruses, and a CMV satellite RNA. HortSci. 35:230-234.

2. Fisher, J. R. 2012. Identification of three distinct classes of satellite RNAs associated with two Cucumber mosaic virus serotypes from the ornamental groundcover Vinca minor. Online. Plant Health Progress doi:10.1094/PHP-2012-0412-01-RS.

3. King, A. M. Q., Adams, M. J., Carstens, E. B., and Lefkowitz, E. J. 2012. Virus Taxonomy, Ninth Report of the International Committee on Taxonomy of Viruses. Secoviridae, pp. 881-899. Elsevier Academic Press. 